\title{
Impact of obesity and diabetes on arthritis: An update*
}

\author{
Rajesh Pandey ${ }^{1}$, Narendra Kumar ${ }^{2}$, Seema Paroha ${ }^{3}$, Ram Prasad ${ }^{4}$, Mukesh Yadav ${ }^{5}$ \\ Shalini Jain ${ }^{6}$, Hariom Yadav ${ }^{6 \#}$ \\ ${ }^{1}$ Department of Biochemistry, Awadhesh Pratap Singh University, Rewa, India \\ ${ }^{2}$ Department of Biotechnology, IMS Engineering College, Ghaziabad, India \\ ${ }^{3}$ Department of Biochemistry, Jawaharlal Nehru Agriculture University, Jabalpur, India \\ ${ }^{4}$ Amity Institute of Microbial Technology, Amity University, Noida, India \\ ${ }^{5}$ College of Advance Studies, Datia, India \\ ${ }^{6}$ NIDDK, National Institutes of Health, Bethesda, USA; ${ }^{\#}$ Corresponding Author: yadavhariom@gmail.com
}

Received 19 November 2012; revised 20 December 2012; accepted 28 December 2012

\begin{abstract}
The incidence of obesity and diabetes has been increased with alarming rate in recent years and became a common problem around the globe including developing as well as in developed countries with incalculable social costs. Obesity and type 2 diabetes are two common co-morbidities occur together. Obesity and diabetes is closely associated with many diseases, osteoarthritis, hypertension, certain form of cancer, sleep-breathing disorders and coronary heart disease. Impacts of obesity and diabetes (insulin resistance) on arthritis have been seen in patients that we associated with combination of various factors like increased availability of highenergy foods, genetic susceptibility and decreased physical activity in modern society. Arthritis is becoming pandemic around the globe and its occurrence with obesity and diabetes has been observed more common than ever. Combination of these two chronic conditions makes these diseases more vulnerable for human health. Till now very limited information is established about the pathological and mechanistic correlation among these health ailments. In this review article we aimed to survey the literature covering the influence of obesity and diabetes on arthritis pathology and tried to establish correlation with these diseases.
\end{abstract}

Keywords: Obesity; Diabetes; Arthritis; Complications

\section{INTRODUCTION}

Obesity and type 2 diabetes have become pandemic

\footnotetext{
*The authors declare no conflict of interest.
}

and most common health risks of the modern society throughout the world. These are chronic diseases with a multifactorial etiology carries to medical problems. World Health Organization estimates that currently more than one billion people are overweight and among them 300 million are obese [1], and these numbers are continuously increasing [2]. It is also reported that weight-related health risk, specifically all-cause mortality, varies with degree of excess weight with those in the obesity grade 3 range faring significantly worse than individuals of normal weight or a lower grade of obesity [3]. The incidence of obesity and elevated body mass index (BMI) has radically augmented in the Western world [4]. Although, the mechanisms coring this increase in fatness are not well understood, it has become more obvious that genetic, environmental factors, socioeconomic and behavioral influences directing to excess caloric ingestion, less physical activity, metabolic and endocrine abnormalities. Obesity and diabetes are well known for augmenting to number of diseases such as hypertension, coronary heart disease (CHD), osteoarthritis [5,6]. Obesity and diabetes turn out to be a major public health issue and efforts to control their spread represent a priority of the public health agenda [7]. It is coupled with bigger morbidity and mortality with an alarming rate [8]. Obesity associated with no.s of diseases such as stroke, ischemic heart disease, hypertensive heart disease, osteoarthritis, post-menopausal breast cancer, colon cancer, endometrial cancer and kidney cancer [7] (Figure 1).

Obesity and diabetes are major risk factors for development of arthritis. More than 80 percent population with type 2 diabetes is obese or overweight and has concern for arthritis. Various forms of arthritis are associated with obesity and diabetes, i.e. periodontal disease is a complication of diabetes mellitus which shows serious health hazard in arthritis cases. Once this disease is established, the chronic features of this infection contribute to worsening disease status leading to more severe dia- 


\begin{tabular}{|c|c|c|}
\hline Pulmonary disease & & Arthritis \\
\hline Heart disease, stroke & & Metabolic syndrome \\
\hline Hyperthyroidism & & Polycystic ovary syndrome \\
\hline Hypertension & Obesity and diabetes: & Dyslipidemia \\
\hline Hernia and inflammation & with other diseases & Asthma, Post menopausal \\
\hline Reproductive abnormality & & Spondlities \\
\hline Cancer & & CVDs, Arthrosclerosis \\
\hline Obstructive sleep apnea & & Liver dysfunction \\
\hline
\end{tabular}

Figure 1. Obesity and diabetes related disease and associated complication or abnormalities.

betes-related complications [8]. Conversely, healing of infection results improvement in diabetes control and a reduce need of diabetes treatment [8]. Various factors are responsible which cause or influences the chances of arthritis that are commonly found in obesity and diabetes pathology. Among them inflammatory reactions are the important common factors that participate in the pathology of all three health ailments.

\section{CAUSES INFLUENCING THE PREVALENCE OF ARTHRITIS}

\subsection{Correlation of Age and Gender with Arthritis}

Most epidemiological studies found that prevalence of arthritis increases with age. However, its relation with obesity prevalence is very variable and may plateau or even decline in very old age groups (75 plus) in some countries. Arthritis affects people of all ages. The elderly have high rates of arthritis. Although the elderly account for just 12 percent of the entire US population, the population with arthritis is split almost evenly between those ages 65 and older and the rest of the population. Just over half of those with arthritis are under age 65, including almost children.

In addition, gender is also considered one of the important factors to involve in the risk of arthritis. The peak prevalence is in women (17\%), which occur in the 60 74 years age range. In recent years it became more complicated to explain the gender differences, as in some communities male are diagnosed with higher arthritis than female resulted in equal prevalence.

\subsection{Life Style Changes and Arthritis Prevalence}

Current working environments and then retirement as well as family conditions lead to more sedentary life styles and increasing reliance on fast foods [9]. Arthritis susceptibility is quite variable in different populations, i.e. certain ethnic groups are particularly susceptible for developing arthritis than the others, when they move from a traditional to an urbanized lifestyle. Such inclination has been found in developing countries [10]. Arthritis is strongly associated with higher body weight or obesity and worldwide prevalence of obesity and diabetes has grown to alarming levels [10].

Obesity is one of the biggest factor to increase arthritis susceptibility and it is has been known that obesity increases almost two times probability of having diabetes in obese subjects [11]. Limited physical activity or work is further reduced in older people due to problems arising from old age leading to a vicious circle [11].

\subsection{Impact of Residence and Socio-Economic Status on Arthritis}

Most epidemiological studies have shown that age and obesity are strongly associated with an increased risk of arthritis [12]. Diabetes and obesity prevalence have strong relations with aggregated disorders, hence countries with more elder population have a higher prevalence of arthritis when compared to developing countries that have generally a younger population. Age and BMI tightly correlated with arthritis prevalence. Lower education level, lower household income, and lower levels of physical activity were associated with a higher prevalence of arthritis [13]. These factors significantly influenced the prevalence of arthritis in elderly Korean women. Cigarette smoking was not significantly associated with the prevalence of arthritis, which is consistent in US women aged 25 - 74 years [14]. Alcohol consumption was associated with a slight decrease in the prevalence of arthritis. Low socioeconomic status related to high disease activity at baseline was recorded on early rheumatoid arthritis in Latin Americans [15].

Arthritis prevalence rate is quite wide in different countries i.e. in Europe arthritis prevalence rate is 5\% - 
$10 \%$, while some countries like Indian and American populations had rates of $20 \%-23 \%$. The maximum rates were found in India and USA. The environmental or lifestyle factors, or both, influences the risk of rheumatoid arthritis. Socio-economic deprivation associated with poor diet and other adverse lifestyle factors that are linked to high rates of arthritis [16].

\section{ARTHRITIS}

Arthritis is refers to more than 100 types rheumatic conditions, both inflammatory and non-inflammatory, affecting joints as well as surrounding structures and other tissues. Many of them are systemic diseases that can cause generalized problems and fatigue with the heart, lungs, skin, kidneys and other parts of the body [17]. There are over 100 different forms of arthritis. The most common form, osteoarthritis, is a result of trauma to the joint, infection of the joint, or age. Other arthritis forms are Rheumatoid arthritis (RA) [18]. The major complaint by individuals who have arthritis is joint pain. Pain is often a constant and may be localized to the affected joint. The pain from arthritis is due to inflammation that occurs around the joint, damage to the joint from disease, daily wear and tear of joint, muscle strains caused by forceful movements against stiff painful joints and fatigue [19]. The common types of arthritis and related conditions: Osteoarthritis (OA), Rheumatoid Arthritis (RA), Fibromyalgia, Osteoporosis and Gout.

\subsection{Osteoarthritis (OA)}

Obesity directly link with OA this may not simply be due to the increased mechanical stresses on joint tissues resulting from increased weight gain in individuals. Additional soluble factors such as adipokines may also play an important role in the onset of OA in obese patients [20]. OA is also a multifactorial disease that leads to a complete alteration of articular cartilage and other related tissues such as subchondral bone. It is a chronic degenerative disease characterized by loss of articular cartilage, hypertrophy of bone at the margins, subchondral sclerosis and the alterations of biochemical and morphological characteristics of the joint capsule and synovial membrane. The histopathological changes include ulceration, softening, synovial inflammation and focal disintegration of the articular cartilage occurs in the late stage of OA. The typical clinical symptoms includes pain, stiffness etc [21]. It is also known as degenerative arthritis, which mostly affects the hands, feet, spine, hips and knees [21]. It is the second most common rheumatological joint disorder with prevalence of $22 \%$ to $39 \%$ in India [22-24]. The locomotor disability is most commonly caused in elder and obese people [20].

\subsection{Fatness Collision and Osteoarthritis}

OA is mostly affects weight-bearing joints such as spine, hip, knee and ankle. Mechanical forces during locomotion over the joints are one of the significant causes of OA. The obesity problem is reaching epidemic proportions in the worldwide, and the increase in weight translates to increased mechanical force on the weightbearing joints. It has become one of the leading causes of disability.

BMI is the common parameter used for obesity diagnostics and is calculated as weight in kilograms divided by height in meters squared $\left(\mathrm{kg} / \mathrm{m}^{2}\right)$ [25-27] and it has been used to establish the correlation of OA and obesity. Coggon and co-workers carried out a population-based case-control study in England in 3 different health districts. In which BMI interacted with other significant risk factors, such as previous meniscectomy, previous knee injury, and presence of Heberden nodes. When these are plotted on a graph, an increase in weight created an exponential rise in OA. In this report authors concluded that the patterns of interaction between the risk factors were similar in both sexes, but the risk associated is higher in women than in men with obesity [25].

In another similar study, Cooper and his co-workers [28] concluded that the obesity and hip injury are important risk factors for $\mathrm{OA}$ that might be accountable to primary prevention. Manninen and co-workers [29], reviewed the social security registry of Finland and found that the relative risk was highest for bilateral knee OA, and there is positive association between relative body weight and OA similar in men and women. These studies showed that the risk for knee OA increased by $36 \%$ for every 2 units of BMI $(5 \mathrm{~kg})$ of weight gain [28,29]. It has also been demonstrated that obesity and OA is associated modest at other sites such as the hip, hand and patellofemoral joint, it suggest that both the metabolic and mechanical factors may be responsible for the link between obesity and OA [30-42].

A study on ambulatory loads in overweight and obese subjects indicated that cartilage thickness at the knee joint responds to loading during gait in a similar manner to OA patients. These findings suggest the possibility that increased weight initiates a pathway of cartilage degeneration prior to the emergence of OA symptoms [43]. In a controlled study on twins, showed that increase in each kilogram body weight was associated with increased risk of radiographic symptoms of OA at the knee and carpometacarpal joint [44]. The strong link between high BMI and knee OA was confirmed in another twin study and this link was found not likely to be mediated by shared genetic factors [45]. Obese patients with knee OA have more joint space narrowing in the medial and lateral tibio-femoral compartments than non-obese patients [46]. 
Obesity is also an important risk factor for the progression of knee OA [47] and has long-term detrimental effects on the knee joint [48]. The role of mechanical factors, specifically malalignment studied mediating in knee OA severity or progression [49]. Although the strong association between knee OA and obesity has been demonstrated, the factors underlying the mechanistic effects have not been elucidated. Age, serum lipids, serum uric acid, blood glucose or diabetes, body fat distribution, blood pressure, smoking, chondrocalcinosis, hysterectomy or estrogen replacement therapy have not been found to affect the obesity and OA relationship [49,50]. However, being overweight is associated with increase in cartilage turnover biomarkers. Cartilage oligomeric matrix protein and collagen type 2 degradation products were increased in individuals with high BMI [51,52].

The association between knee structural alteration and BMI was evaluated in a cross-sectional study including 372 healthy subjects [53]. This study shows that increasing BMI may induce cartilage defects even in those with no radiographic OA, and reasons behind this are completely unknown. Authors of this study proposed that a greater BMI can induce larger knee subchondral bone size or that knee subchondral bone may respond to higher loads by expansion of the joint surface area [53].

\subsection{Association of Obesity and Rheumatoid Arthritis}

Rheumatoid arthritis (RA) is a chronic, inflammatory autoimmune disease that causes the immune system to attack the joints. It is a disabling and painful inflammatory condition, which can lead to loss of mobility due to pain and joint destruction. In this condition, commonly small joints are affected, but larger joints are also affected [54]. The risk of RA is higher in women between 40 and 50 years of age, and later age in men [55]. The disease is symmetric, especially as it progresses, and favors the interphalangeal joints of the hands and feet, such as the proximal interphalangeal, metacarpophalangeal, and metatarsophalangeal joints, as well as the wrist and ankle. Joint swelling, deformity, pain, stiffness, and weakness are classic symptoms. Other includes tenderness, synovial thickening, effusion, erythema, and decreased range of motion, ankylosis, and subluxation [56]. RA is common inflammatory arthropathy worldwide and affects up to $0.75 \%$ of the Indian population [57-59]. Obesity and RA have been tightly correlated in various studies [60-62].

\subsection{Obesity Induced Fibromyalgia}

Fibromyalgia is a medical condition that appears to involve disordered afferent processing which is associated with multiple symptoms like chronic widespread pain, fatigue, sleep disturbances, and cognitive alterations. The core symptoms seen in individuals with fibromyalgia are multifocal pain, fatigue severe enough to limit daily activities, sleep disturbances, cognitive or memory problems, and, in many cases, psychological distress $[64,65]$. These symptoms and syndromes occur approximately 1.5 - 2 times more commonly in women than men. The sex difference appears more apparent in clinical samples than in population-based samples [66,67].

A number of risk factors are associated with this condition and obesity plays a key role in fibromyalgia's pathology [68]. In a pilot study of overweight and obese women with fibromyalgia, the relationship between BMI and fibromyalgia symptoms were assessed after a 20week behavioral weight loss treatment [69]. Participants lost, on average, $4.4 \%$ of their initial weight, and weight loss predicted a reduction in fibromyalgia symptoms, pain interference, body satisfaction and quality of life. In a study of obese subjects undergoing bariatric surgery, there was a significant reduction in fibromyalgia syndrome at follow-up 6 - 12 months later [70].

\subsection{Impact of Obesity on Osteoporosis}

Osteoporosis is characterized by low bone mass and microarchitectural deterioration of bone tissue. Osteoporosis is a reduction in the quantity of bone or atrophy of skeletal tissue; an age-related disorder characterized by decreased bone mass and loss of normal skeletal microarchitecture, leading to increased susceptibility to fractures. About 3 million people have osteoporosis in the UK, causing approximately 230,000 fractures each year, according to the National Health Service (NHS). Osteoporosis is a public health threat for an estimated 44 million people in the USA, 55\% of people aged 50 or over, says the National Osteoporosis Foundation (NOF). The NOF says that 10 million people currently have osteoporosis, while 34 million are thought to have low bone mass; which places them at significantly increased risk for the condition. At a given age, bone mass results from the amount of bone acquired during growth, i.e. the peak bone mass minus the age-related bone loss which particularly accelerates after menopause [71]. The rate and magnitude of bone mass gain during the pubertal years and of bone loss in later life may markedly differ from one skeletal site to another, as well as from one individual to another. Bone mass gain is mainly related to increases in bone size that is in bone external dimensions, with minimal changes in bone microarchitecture [72].

A number of studies have demonstrated that body weight is closely correlated with bone mineral density (BMD) [73-75]. In cross-sectional studies, a $10 \mathrm{~kg}$ increase in body weight is associated with approximately a 
$1 \%$ increase in BMD. This relationship has been demonstrated for both women and men and across cultures but the effect of weight on BMD appears to be stronger in women than in men, [76-78] and more in postmenopausal than premenopausal women [79,80]. Several mechanisms have been proposed to explain the effect of weight on bone density. Firstly, it could be due to the amount of adipose tissue, which is the major site of conversion of androgens to estrogen in both elderly men and women. If estrogen has a greater role in preservation of bone mass in women than men, this may explain why the effect of weight is greater in women than men. This may also explain why shortly after menopause, obese women do not lose bone as rapidly as their non-obese counterparts [64, 65]. A second mechanism relates to the increased mechanical load that heavier individuals place on weightbearing bones. This is supported by some data suggesting that body size is a better determinant in weight bearing rather than non-weight bearing sites [78]. Another study showed that overweight postmenopausal women may be more susceptible to bone loss with weight reduction. Weight loss correlated with BMD loss at the trochanter but not at the femoral neck in the group receiving normal calcium intake daily compared to high calcium intake [81]. Weight loss due to caloric restriction appears to induce rapid bone loss at clinically important sites of fracture, unlike exercise-induced weight loss [82]. In addition, the rapid increase in obesity has led to an escalation in the uptake of surgical techniques to control weight. Procedures that involve duodenal bypassing place individuals at risk for osteoporosis as this is the primary site for calcium absorption [83-85].

\subsection{Obesity and Inflammatory Arthritis}

Gout is an inflammatory arthritis triggered by the crystallization of uric acid within the joints and is often associated with hyperuricemia. Acute gout is typically intermittent, constituting one of the most painful conditions experienced by humans. In addition to the morbidity that is attributable to gout itself, the disease is associated with such conditions as the insulin resistance, hypertension, nephropathy, and disorders associated with increased cell turnover [86,87]. The overall disease burden of gout remains substantial and may be increasing. The prevalence of self-reported, physician-diagnosed gout in the Third National Health and Nutrition Examination Survey was found to be greater than $2 \%$ in men older than 30 years of age and in women older than 50 years of age [88]. The prevalence increased with increasing age and reached $9 \%$ in men and $6 \%$ in women older than 80 years of age [89]. Dietary and lifestyle trends and the increasing prevalence of obesity and the metabolic syndrome may explain the increasing incidence of gout.
Gout is the most common form of crystal-induced arthritis and in the United States affects more than 1\% of adults [90]. Obesity is a well-known modifiable risk factor in the pathogenesis of gout and serum uric acid is positively associated with BMI [91]. The size of the visceral fat area is the strongest contributor to elevated serum uric acid concentration, decreased uric acid clearance and increased urinary uric acid/creatinine ratio [92]. Although, weight loss is advocated in the overall management of gout, however no study has assessed the effect of weight reduction on uric acid levels or attacks of gout.

\subsection{Diabetes and Arthritis}

Diabetes mellitus (DM) is a chronic disease and has become one of the main threats to human health in recent decades. Diabetes worldwide was estimated at between 151 million and 171 million in the year 2000 and, it is estimated that this number will triple by 2050. Type 1 diabetes is characterized by beta-cell failure, partly due to autoimmune destruction [93] and Type 2 diabetes arises as a result of beta-cell failure combined with associated insulin resistance [94]. In type 2 diabetes, increased hepatic glucose production is considered to play a key role in fasting, as well as postprandial hyperglycemia, and increased gluconeogenesis seems to be needed [95, 96]. Uncontrolled diabetes with increased blood glucose is strongly correlated to causing long-term microvascular and macrovascular complications, such as nephropathy, neuropathy, retinopathy, muscular dystrophy and atherosclerosis [97-101]. There are various anti-diabetic compounds are documented in management of diseases and its complications [102], but long term consumption of these also poses other health threats.

Physical activity is key component of DM and arthritis management [103]. Arthritis which is a barrier to physical activity [104], is the most common cause of disability [105]. DM and arthritis each produce large burdens on world medical budget [106]; they also share some risk factors including age and obesity [107]. The mechanism of this comorbidity remain uncertain; these co-occurring conditions have been associated with a significant reduction in quality of life and increased risk for other severe complications [108]. Understanding the extent to which arthritis produces activity limitation among adults with DM will help raise awareness of the conjoint burden of these two diseases as well as the need of efforts to promote the benefits of physical activity in managing DM and arthritis. A recent most study in USA among adults with DM, the unadjusted prevalence of arthritis was 48.1\% (9.6 million) and 55.0\% (5.3 million), respectively. After adjusting for other characteristics, the prevalence ratios of arthritis and of arthritis-attributable ac- 
tivity limitation (AAAL) among arthritic adults with versus without DM (95\% CI) were 1.44 (1.35 - 1.52) and $1.21(1.15$ - 1.28), respectively.

The Centers for Disease Control and Prevention estimate that $>26 \%$ of adults over 65 have DM, and noted that diabetes is a key mortality predictor in patients with RA [109,110]. Both RA and diabetes increase the risk of arthritis. The prevalence of arthritis increased with age and BMI and was higher for women, non-Hispanic whites, and inactive adults compared with their counterparts both among adults with and without DM. Among US adults with diagnosed DM, nearly half also have diagnosed arthritis; moreover, more than half of those with both diseases had AAAL. Arthritis can be a barrier to physical activity among adults with diagnosed DM [111].

From various arthritic and rheumatological manifestations, shoulder hand syndrome (SHS), diabetic hand syndrome (DHS), diffuse idiopathic skeletal hyperostosis (DISH) and neuroarthropathy are characteristically associated with DM. Rheumatological diseases are now common, which have an increased prevalence in the diabetic population [112]. All these have a severe clinical course in the diabetic population [113]. There are various reports available in literature [114] regarding rheumatological manifestations in diabetic patients.

The association in between diabetes and frozen shoulder is well documented. An incidence of frozen shoulder is reported by Bridgmen was $11 \%$ among diabetic patients. DHS is also known as diabetic cheiroarthropathy or syndrome of limited joint mobility. It was first reported by Jung et al. $[115,116]$ in adults with diabetes and Grgic et al. [117] in paediatric diabetics. Most of the studies suggest a prevalence of about 35\% [118,119]. SHS is a special feature in diabetes. The most common cause is trauma apart from other conditions like diabetes, cerebrovascular accident, post-myocardial infarction, barbiturates etc. Association of SHS with diabetes has been reported by Steinbrocker and Argyros [120,121]. Osteoarthritis and diabetes have a positive correlation. Crisp and Heathcoate reported higher incidence in young and middle aged diabetics. Moreover, joint damage starts at an earlier age and is much more severe [122]. DISH, especially of spine, frontalis interna and calcification of the pelvic ligaments were found to be increased in Type 2 DM. In the study by Holt, it was 25\% amongst 428 diabetic patients [123,124].

In a study using a large administrative database, subjects with RA were found to have a $50 \%$ increase in the risk of DM, even after controlling for glucocorticoid use [125]. These findings relate with earlier administrative database study that found a $40 \%$ increase in DM associated with RA [126]. Other studies also found an increased prevalence of DM in RA [126,127]. Finally, a population-based study also found an increase in the risk of DM associated with RA [128]. One study examined DM in RA and found a strong relationship with DM overall, but this was only significant for type $1 \mathrm{DM}$ and not type 2 DM [129-131].

\subsection{Diabetes with Osteoporosis}

Type 1 diabetes is linked to low bone density and typically occurs at early age resulting the bone mass is still increasing. Insulin, which is deficient in type 1 diabetes patients, may promote bone growth, size, shape and strength. Diabetes type 1 subjects achieve lower peak bone mass with maximum strength and density which indirectly increases the risk of osteoporosis. Mostly people with type 1 diabetes also have celiac disease symptoms associated with reduced bone mass.

Diabetes prevalence increases sharply with age, and it is projected that by the year 2025, the majority of persons with diabetes will be aged 65 years or older [132, 133]. Although diabetes is often accompanied by vascular and neuropathic comorbidities [134], the threats of physical disability, loss of independence, and diminished quality of life may ultimately be the greatest concern this disease and its associated many complications. Crosssectional data from nationally representative surveys show that $50 \%$ of older people with diabetes report difficulty performing daily physical tasks, such as climbing stairs, but few prospective studies have examined the specific impact of diabetes on incident disability or how it may act through its comorbidities [135-137]. Additionally, no prospective studies have assessed the predictors of disability among women with diabetes.

The relationship between diabetes and disability is likely due to multiple factors, because diabetes is related to numerous vascular and neuropathic complications that could conceivably affect functional status [138-143]. The potential role of insulin resistance as a cardiovascular risk factor in patients with inflammatory arthritis has been examined by Svenson, et al., who reported impaired glucose handling in a sample of RA patients compared to controls [144]. These investigators also found evidence of an inverse relationship between insulin sensitivity and acute phase markers in RA. More recently, Dessein, et al. reported significantly higher levels of insulin resistance in patients with inflammatory arthritis compared with controls, and an association between high CRP concentrations and insulin resistance $[145,146]$. Glucocorticoids, which are commonly used in RA therapy, would also be expected to contribute to insulin resistance [147]. Given that chronic systemic inflammation has been associated with both insulin resistance and type $2 \mathrm{DM}$, the question arises whether the prevalence of DM is increased in patients with RA. Although no studies to date have directly addressed this question, it has been indirectly examined 
in some of the studies addressing cardiovascular risk in RA. The results of these studies have been conflicting. Han, et al., using a clinic-based population, found a significantly higher prevalence of type $2 \mathrm{DM}$ in RA patients compared with matched controls [148]. However, contrasting findings were reported from 2 large cohort studies. Solomon and colleagues did not find evidence of an association between RA and DM in a prospective cohort of women [149]. Although delRincon and colleagues noted a significantly higher frequency of diabetes in a cohort of patients with RA compared with that in a population-based cohort of persons without RA, this difference disappeared when the samples were stratified for age [150].

Simard and Mittleman's population-based study is the first to directly address the question of an association between prevalent RA and DM [151]. These investigators used population-based data collected as part of the National Health and Nutrition Examination Survey (NHANES) III, which included 5302 study subjects aged $>60$ years. A total of 144 of these subjects fulfilled criteria for RA, of whom 24 had prevalent diabetes. After controlling for a number of potential confounding factors, including demographic factors, body mass index, physical inactivity, and glucocorticoid prescription, a significant association between RA and DM was not found. These findings must, however, be interpreted in light of the limitations of this study. In particular, the numbers of subjects with RA and DM are very small. This is reflected in the wide confidence intervals of the odds ratios, and suggests that the study may not have adequate power to pick up a moderate association between these 2 conditions. It is worth noting in this context that the adjusted odds ratios for DM in the subset of RA subjects not currently taking glucocorticoids and fasting for at least 8 hours prior to blood draw ranged from 1.29 to 1.57 , although again, these findings were not statistically significant.

As an additional concern, included subjects with RA had very mild disease. Only $10 \%$ of RA cases were taking disease-modifying drugs, and mean CRP level was only $1.04 \mathrm{mg} / \mathrm{dl}$. Further, the proportion of patients with positive rheumatoid factor was smaller than that seen in other population-based studies of RA [152,153]. Even given the community based setting of this study, these results are surprising and suggest the possibility that patients in the community with more severe RA did not participate in NHANES due to disease-related disability. This would mean the sample of subjects with RA in this study is not representative of all patients with RA. Because DM might be expected to occur more often in patients with more severe RA, who have higher levels of inflammation, the noted prevalence of DM in these patients may be an underestimation. Other factors that may have led to dilution of a true association between RA and DM include the cross-sectional design of the data used in this study. If patients with both RA and DM in the community had increased mortality, the number of survivors in this group would be lower, thus leading to underestimation of the concurrence of these 2 conditions. Further, due to missing data on fasting glucose in a large number of study participants, the prevalence of diabetes could have been underestimated due to asymptomatic patients with type 2 DM not having been included. Finally, the criteria used for definition of RA could have allowed inclusion of patients with other forms of inflammatory arthritis, thus diluting an association between RA and DM. Given the limitations outlined above, an association between RA and DM has not yet been ruled out, despite the lack of a significant association noted in this study. Rather, these findings point to the need for further investigation of this interesting question. Future studies would ideally be prospective, use predefined criteria for diagnosis of both RA and DM, and include larger numbers than in the current study.

The study reported by Simard and Mittleman, along with most recent studies examining the association between RA and DM, have concentrated on type 2 DM. This is of particular interest at present due to the association of this condition with systemic inflammation. There are also, however, reasons for speculation about a possible association between type $1 \mathrm{DM}$ and RA. These include evidence of familial clustering of autoimmune diseases, including RA and type $1 \mathrm{DM}$, and the common association of the HLA-DR4 allele with both DM and RA [154]. One study found that $13 \%$ of 295 RA patients had a first-degree relative with type 1 diabetes [154]. However, another study that examined a cohort of hospitalized RA patients found a prevalence of type $1 \mathrm{DM}$ in the RA cohort similar to that in the general population [154]. Simard and Mittleman do not specify whether they included both type 1 and $2 \mathrm{DM}$, but given that all patients included in the study were over 60 years of age, it is likely that the majority of patients included in this study had type 2 DM. Chronic systemic inflammation has been clearly shown to predispose to premature atherosclerosis and cardiovascular risk in patients with RA. Chronic inflammation also appears to predispose to development of both insulin resistance and DM. The important question remains whether there is an increased prevalence of DM in patients with RA. Ideally, largescale, prospective studies are needed to gain a clearer picture of the true prevalence of DM in RA patients in the community.

\section{CONCLUSION}

Obesity has been the problem of effluent society of 
developing and developed worlds. Hence the diseases which are common manifestation of obesity are prevalent in obese persons. Diet and exercise interventions to reduce obesity are potentially cost-effective but have a negligible impact on the total body weight-related disease burden Obesity is associated with a number of musculoskeletal conditions and is responsible for significant disability and impaired quality of life. The global obesity epidemic has significant consequences for both the individual and the community in terms of direct and indirect health-care costs. Further studies prospectively evaluating these conditions in the obese population are imperative to define better the mechanisms by which obesity mediates musculoskeletal disorders, and to determine the effects of moderate to large weight loss on these conditions. This has important ramifications in both the prevention and development of appropriate treatment strategies in the ongoing management of these conditions.

\section{REFERENCES}

[1] Zimmet, P. and Thomas, C.R. (2003) Genotype, obesity and cardiovascular disease-Has technical and social advancement outstripped evolution? Journal of International Medicine, 254, 114-125.

[2] Rashid, M.N., Fuentes, F., Touchon, R.C. and Wehner, P.S. (2003) Obesity and the risk for cardiovascular disease. Preventive Cardiology, 6, 42-47. doi:10.1111/j.1520-037X.2003.01358.X

[3] Calle, E.E., Thun, M.J., Petrelli, J.M., Rodriguez, C. and Heath, C.W. (1999) Body mass index and mortality in a prospective cohort of US adults. England Journal of Medicine, 341, 1097-1105.

[4] Kopelman, P.G. (2000) Obesity as a medical problem. Nature, 404, 635-643.

[5] McGinnis, J.M. and Foege, W.H. (1993) Actual causes of death in the United States. JAMA, 270, 2207-2212. doi:10.1001/jama.1993.03510180077038

[6] Friedman, J.M. (2000) Obesity in the new millennium. Nature, 404, 632-634.

[7] Loe, H. (1993) Periodontal disease. The sixth complication of diabetes mellitus. Diabetes Care, 16, 329-334.

[8] Grossi, S.G. and Genco, R.J. (1998) Periodontal disease and diabetes mellitus: A two-way relationship. Annual Periodontology, 3, 51-61. doi:10.1902/annals.1998.3.1.51

[9] Parkinson, L., Gibson, R., Robinson, I. and Byles, J. (2010) Older women arthritis: Tracking impact over time. Australas Journal of Ageing, 29, 155-160. doi:10.1111/j.1741-6612.2010.00422.x

[10] Ndetan, H., Evans Jr., M.W., Felini, M., Bae, S., Rupert, R. and Singh, K.P. (2010) Chiropractic and medical use of health promotion in the management of arthritis: Analysis of the 2006 National Health Interview Survey.
Journal of Manipulative Physiology Therapy, 33, 419424. doi:10.1016/j.jmpt.2010.06.008

[11] Elders, M.J. (2008) The increasing impact of arthritis on public health. Journal of Rheumatology, 60, 6-8.

[12] Janssen, I. and Mark, A.E. (2006) Separate and combined influence of body mass index and waist circumference on arthritis and knee osteoarthritis. International Journal of Obesity, 30, 1223-1228. doi:10.1038/sj.ijo.0803287

[13] Zakkak, J.M., Wilson, D.B. and Lanier, J.O. (2009) The association between body mass index and arthritis among US adults: CDC's surveillance case definition. Prevention of Chronic Disease, 6, A56.

[14] Busija, L., Hollingsworth, B., Buchbinder, R. and Osborne, R.H. (2007) Role of age, sex, and obesity in the higher prevalence of arthritis among lower socioeconomic groups: A population-based survey. Arthritis Rheumatology, 57, 553-561.

[15] Mili, F., Helmick, C.G. and Zack, M.M. (2002) Prevalence of arthritis: Analysis of data from the US Behavioral Risk Factor Surveillance System, 1996-99. Journal of Rheumatology, 29, 1981-1988.

[16] James, N.T., Miller, C.W., Fos, P.J., Zhang, L., Wall, P. and Welch, C. (2003) Health status, physical disability, and obesity among adult Mississippians with chronic joint symptoms or doctor-diagnosed arthritis: Findings from the Behavioral Risk Factor Surveillance System. Prevention of Chronic Disease, 5, 85.

[17] Manninen, P., Riihimaki, H., Heliovaara, M. and Makela P. (1996) Overweight, gender and knee osteoarthritis. International Journal of Obesity Related Metabolism and Disorder, 6, 595-597.

[18] Centers for Disease Prevention and Health Promotion (2010) Arthritis: The nation's most common cause of disability.

[19] Wollenhaupt, J. and Zeidler, H. (1998) Undifferentiated arthritis and reactive arthritis. Current Opinion in Rheumatology, 4, 306-313. doi:10.1097/00002281-199807000-00005

[20] Martin, J.A. and Buckwalter, J.A. (2003) Aging, articular cartilage chondrocyte senescence and osteoarthritis. Biogerontology, 3, 257-264. doi:10.1023/A:1020185404126

[21] Dicesare, P.E. and Abramson, S.B. (2005) Pathogenesis of osteoarthritis. In: Harris, E.D., Budd, R.C., Genovese, M.C., et al., Eds., Kelley's Textbook of Rheumatology, 7th Edition, Elsevier Saunders, St. Louis.

[22] Chopra, A., Patil, J. and Bilampelly, V. (1997) The Bhigwan (India) COPCORD: Methodology and first information report, APLAR. Journal of Rheumatology, 1, 145154.

[23] Chopra, A., Patil, J., Bilampelly, V., Relwane, J. and Tandle, H.S. (2001) Prevalence of rheumatic disease in rural population in Western India. Journal of Association Physicians India, 49, 240-246.

[24] Mahajan, A., Jasrotia, D.S., Manhas, A.S. and Jamwal, S.S. (2003) Prevalence of major rheumatic disorders in Jammu. JK Science, 5, 63-66.

[25] Hedley, A.A., Ogden, C.L., Johnson, C.L., Carroll, M.D., 
Curtin, L.R. and Flegal, K.M. (2004) Prevalence of overweight and obesity among US children, adolescents, and adults, 1999-2002. JAMA, 291, 2847-2850. doi:10.1001/jama.291.23.2847

[26] Coggon, D., Reading, I., Croft, P., McLaren, M., Barrett, D. and Cooper, C. (2001) Knee osteoarthritis and obesity. International Journal of Obesity, 25, 622-627. doi:10.1038/sj.ijo.0801585

[27] Parvizi, J., Trousdale, R.T. and Sarr, M.G. (2000) Total joint arthroplasty in patients surgically treated for morbid obesity. Journal of Arthroplasty, 15, 1003-1007. doi:10.1054/arth.2000.9054

[28] Cooper, C., Inskip, H., Croft, P., et al. (1998) Individual risk factors for hip osteoarthritis: Obesity, hip injury, and physical activity. American Journal of Epidemiology, 147, 516-522. doi:10.1093/oxfordjournals.aje.a009482

[29] March, L.M. and Bagga, H. (2004) Epidemiology of osteoarthritis in Australia. Medical Journal of Australia, 180, S6-S10.

[30] Felson, D.T., Anderson, J.J., Naimark, A., Walker, A.M. and Meenan, R.F. (1988) Obesity and knee osteoarthritis. The Framingham Study. Annual International Medicine, 109, 18-24.

[31] Felson, D.T., Zhang, Y., Anthony, J.M., Naimark, A. and Anderson, J.J. (1992) Weight loss reduces the risk for symptomatic knee osteoarthritis in women. The Framingham Study. Annual International Medicine, 116, 535539.

[32] Felson, D.T., Zhang, Y., Hannan, M.T., Naimark, A., Weissman, B., Aliabadi, P., et al. (1997) Risk factors for incident radiographic knee osteoarthritis in the elderly: The Framingham Study. Arthritis Rheumatology, 40, 728733. doi:10.1002/art.1780400420

[33] Hart, D.J., Doyle, D.V. and Spector, T.D. (1999) Incidence and risk factors for radiographic knee osteoarthritis in middle-aged women: The Chingford Study. Arthritis Rheumatology, 42, 17-24. doi:10.1002/1529-0131(199901)42:1<17::AID-ANR2>3. $0 . \mathrm{CO} ; 2-\mathrm{E}$

[34] Davis, M.A., Ettinger, W.H. and Neuhaus, J.M. (1988) The role of metabolic factors and blood pressure in the association of obesity with osteoarthritis of the knee. Journal of Rheumatology, 15, 1827-1832.

[35] Hochberg, M.C., Lethbridge-Cejku, M., Scott Jr., W.W., Reichle, R., Plato, C.C. and Tobin, J.D. (1995) The association of body weight, body fatness and body fat distribution with osteoarthritis of the knee: Data from the Baltimore Longitudinal Study of Aging. Journal of Rheumatology, 22, 488-493.

[36] Bagge, E., Bjelle, A., Eden, S., and Svanborg, A. (1991) Factors associated with radiographic osteoarthritis: Results from the population study 70-year-old people in Goteborg. Journal of Rheumatology, 18, 1218-1222.

[37] Cicuttini, F.M., Spector, T. and Baker, J. (1997) Risk factors for osteoarthritis in the tibiofemoral and patellofemoral joints of the knee. Journal of Rheumatology, 24, 1164-1167.

[38] Anderson, J.J. and Felson, D.T. (1988) Factors associated with osteoarthritis of the knee in the first national Health and Nutrition Examination Survey (HANES I). Evidence for an association with overweight, race, and physical demands of work. American Journal of Epidemiology, 128, 179-189.

[39] Schouten, J.S., van den Ouweland, F.A. and Valkenburg, H.A. (1992) A 12 year follow up study in the general population on prognostic factors of cartilage loss in osteoarthritis of the knee. Annual Rheumatology Disease, 51, 932-937. doi:10.1136/ard.51.8.932

[40] Ledingham, J., Regan, M. and Jones, A. (1995) Doherty M. Factors affecting radiographic progression of knee osteoarthritis. Annual Rheumatogoly Disease, 54, 53-58. doi:10.1136/ard.54.1.53

[41] Kaipiainen-Seppanen, O., Aho, K., Isomaki, H. and Laakso, M. (1996) Incidence of rheumatoid arthritis in Finland during 1980-1990. Annual Rheumatology Disease, 55, 608-611. doi:10.1136/ard.55.9.608

[42] Dougados, M., Gueguen, A., Nguyen, M., Thiesce, A., Listrat, V. and Jacob, L. (1992) Longitudinal radiologic evaluation of osteoarthritis of the knee. Journal of Rheumatology, 19, 378-384.

[43] Andriacchi, T.P. and Mundermann, A. (2006) The role of ambulatory mechanics in the initiation and progression of knee osteoarthritis. Current Opinion Rheumatology, 18, 514-518. doi:10.1097/01.bor.0000240365.16842.4e

[44] Cicuttini, F.M., Baker, J.R. and Spector, T.D. (1996) The association of obesity with osteoarthritis of the hand and knee in women: A twin study. Journal Rheumatology, 23, 1221-1226.

[45] Manek, N.J., Hart, D., Spector, T.D. and MacGregor, A.J. (2003) The association of body mass index and osteoarthritis of the knee joint: An examination of genetic and environmental influences. Arthritis Rheumatology, 48, 1024-1029. doi:10.1002/art.10884

[46] Cimen, O.B., Incel, N.A., Yapici, Y., Apaydin, D. and Erdogan, C. (2004) Obesity related measurements and joint space width in patients with knee osteoarthritis. Journal of Medecine and Science, 109, 159-164.

[47] Spector, T.D., Hart, D.J. and Doyle, D.V. (1994) Incidence and progression of osteoarthritis in women with unilateral knee disease in the general population: The effect of obesity. Annual Rheumatology Disease, 53, 565568. doi:10.1136/ard.53.9.565

[48] Szoeke, C., Dennerstein, L., Guthrie, J., Clark, M. and Cicuttini, F. (2006) The relationship between prospectively assessed body weight and physical activity and prevalence of radiological knee osteoarthritis in postmenopausal women. Journal of Rheumatology, 33, 18351840.

[49] Sharma, L., Lou, C., Cahue, S. and Dunlop, D.D. (2004) The mechanism of the effect of obesity in knee osteoarthritis: The mediating role of malalignment. Arthritis Rheumatology, 43, 568-575. doi:10.1002/1529-0131(200003)43:3<568::AID-ANR13> 3.0.CO;2-E

[50] Felson, D.T., Goggins, J., Niu, J., Zhang, Y. and Hunter, D.J. (2004) The effect of body weight on progression of 
knee osteoarthritis is dependent on alignment. Arthritis Rheumatology, 50, 3904-3909. doi:10.1002/art.20726

[51] Jordan, J.M., Luta, G., Stabler, T., Renner, J.B., Dragomir, A.D. and Vilim, V. (2003) Ethnic and sex differences in serum levels of cartilage oligomeric matrix protein: The Johnston County Osteoarthritis Project. Arthritis Rheumatology, 48,675-681.

[52] Mouritzen, U., Christgau, S., Lehmann, H.J., Tanko, L.B. and Christiansen, C. (2003) Cartilage turnover assessed with a newly developed assay measuring collagen type II degradation products: influence of age, sex, menopause, hormone replacement therapy, and body mass index. Annual Rheumatoloy Disease, 62, 332-336. doi:10.1136/ard.62.4.332

[53] Ding, C., Cicuttini, F., Scott, F., Cooley, H. and Jones, G. (2005) Knee structural alteration and BMI: A cross-sectional study. Obesity Research, 13, 350-361. doi:10.1038/oby.2005.47

[54] Majithia, V. and Geraci, S.A. (2007) Rheumatoid arthritis: Diagnosis and management. American Journal of Medicine, 120, 936-939. doi:10.1016/j.amjmed.2007.04.005

[55] Alamanos, Y., Voulgari, P.V. and Drosos, A.A. (2005) Incidence and prevalence of rheumatoid arthritis, based on the 1987. American College of Rheumatology Criteria: A systematic review. Arthritis Rheumatology, 36, 182188.

[56] Lee, D.M. and Weinblatt, M.E. (2001) Rheumatoid arthritis. Lancet, 358, 903-911. doi:10.1016/S0140-6736(01)06075-5

[57] Kobelt, G., Jonsson, L. and Lindgren, P. (2002) Modeling the progression of rheumatoid arthritis: A two country model to estimate costs and consequences of rheumatoid arthritis. Arthritis Rheumatology, 46, 2310-2319. doi:10.1002/art.10471

[58] Malaviya, A.N., Kapoor, S.K. and Singh, R.R. (1993) Prevalence of rheumatoid arthritis in the adult Indian Population. Rheumatology International, 13, 131-134. doi:10.1007/BF00301258

[59] Kumar, N., Singh, S., Patro, N. and Patro, I. (2009) Evaluation of protective efficacy of Spirulina platensis against collagen induced arthritis in rats. Inflammopharmacology, 17, 181-190. doi:10.1007/s10787-009-0004-1

[60] Symmons, D.P. (2005) Looking back: Rheumatoid arthritis Faetiology, occurrence and mortality. Rheumatology, 44, iv14-iv17. doi:10.1093/rheumatology/kei055

[61] Symmons, D.P., Bankhead, C.R., Harrison, B.J., Brennan, P., Barrett, E.M. and Scott, D.G. (1997) Blood transfusion, smoking, and obesity as risk factors for the development of rheumatoid arthritis: Results from a primary carebased incident case-control study in Norfolk, England. Arthritis Rheumatology, 40, 1955-1961. doi:10.1002/art.1780401106

[62] Voigt, L.F., Koepsell, T.D., Nelson, J.L., Dugowson, C.E. and Daling, J.R. (1994) Smoking, obesity, alcohol consumption, and the risk of rheumatoid arthritis. Epidemiology, 5, 525-532.

[63] Escalante, A. and Haas, R.W. (2005) Paradoxical effect of body mass index on survival in rheumatoid arthritis: Role of comorbidity and systemic inflammation. Arch International Medicine, 165, 1624-1629.

doi:10.1001/archinte.165.14.1624

[64] Perrot, S., Dickenson, A.H. and Bennett, R.M. (2008) Fibromyalgia: Harmonizing science with clinical practice considerations. Pain Practice, 8,177-189.

doi:10.1111/j.1533-2500.2008.00190.x

[65] Lawrence, R.C., Felson, D.T., Helmick, C.G., Arnold, L.M., Choi, H., Deyo, R.A., Gabriel, S., Hirsch, R., Hochberg, M.C., Hunder, G.G., Jordan, J.M., Katz, J.N., Kremers, H.M. and Wolfe, F. (2008) Estimates of the prevalence of arthritis and other rheumatic conditions in the United States, part II. Arthritis Rheumatology, 58, 2635. doi:10.1002/art.23176

[66] Marcus, D.A. (2009) Fibromyalgia diagnosis and treatment options. Gender Medicine, 2, 139-151. doi:10.1016/j.genm.2009.01.004

[67] Williams, D.A. and Clauw, D.J. (2009) Understanding fibromyalgia: Lessons from the broader pain research community. Journal of Pain, 10, 777-791. doi:10.1016/j.jpain.2009.06.001

[68] Thompson, D., Lettich, L. and Takeshita, J. (2003) Fibromyalgia: An overview. Current Psychiatry Report, 5, 211-217. doi:10.1007/s11920-003-0045-X

[69] Shapiro, J.R., Anderson, D.A. and Danoff-Burg, S. (2005) A pilot study of the effects of behavioral weight loss treatment on fibromyalgia symptoms. Journal Psychosomic Research, 59, 275-282.

[70] Moskowitz, R.W. (2001) Musculoskeletal findings in obese subjects before and after weight loss following bariatric surgery. International Journal of Obesity, 31, 114-120

[71] Bonjour, J.P., Theintz, G., Buchs, B., Slosman, D. and Rizzoli, R. (1991) Critical years and stages of puberty for spinal and femoral bone mass accumulation during adolescence. Journal of Clinical Endocrinology and Metabolism, 73, 555-563. doi:10.1210/jcem-73-3-555

[72] Theintz, G., Buchs, B., Rizzoli, R., Slosman, D., Clavien, H., Sizonenko, P.C. and Bonjour J.P. (1992) Longitudinal monitoring of bone mass accumulation in healthy adolescents: Evidence for a marked reduction after 16 years of age at the levels of lumbar spine and femoral neck in female subjects. Journal of Clinical Endocrinology and Metabolism, 75, 1060-1065. doi:10.1210/jc.75.4.1060

[73] Nguyen, T.V., Kelly, P.J., Sambrook, P.N., Gilbert, C., Pocock, N.A. and Eisman, J.A. (1994) Lifestyle factors and bone density in the elderly: Implications for osteoporosis prevention. Journal of Bone Miner Research, 9, 1339-1346. doi:10.1002/jbmr.5650090904

[74] Bauer, D.C., Browner, W.S., Cauley, J.A., Orwoll, E.S., Scott, J.C. and Black, D.M. (1993) Factors associated with appendicular bone mass in older women. The Study of Osteoporotic Fractures Research Group. Annual International Medicine, 118, 657-665.

[75] Kroger, H., Tuppurainen, M., Honkanen, R., Alhava, E. and Saarikoski, S. (1994) Bone mineral density and risk factors for osteoporosis population-based study of 1600 perimenopausal women. Calcified Tissue International, 


\section{5, 1-7. doi:10.1007/BF00310160}

[76] Pluijm, S.M., Visser, M., Smit, J.H., Popp-Snijders, C., Roos, J.C. and Lips, P. (2001) Determinants of bone mineral density in older men and women: Body composition as mediator. Journal of Bone Miner Research, 16, 21422151. doi:10.1359/jbmr.2001.16.11.2142

[77] Felson, D.T., Zhang, Y., Hannan, M.T. and Anderson, J.J. (1988) Effects of weight and body mass index on bone mineral density in men and women: The Framingham study. Journal Bone Miner Research, 8, 567-573. doi:10.1002/jbmr.5650080507

[78] Edelstein, S.L. and Barrett-Connor, E. (1993) Relation between body size and bone mineral density in elderly men and women. American Journal of Epidemiology, 138, 160-169.

[79] Liel, Y., Edwards, J., Shary, J., Spicer, K.M., Gordon, L. and Bell, N.H. (1988) The effects of race and body habitus on bone mineral density of the radius, hip, and spine in premenopausal women. Journal of Clinical Endocrinology Metabolism, 66, 1247-1250. doi:10.1210/jcem-66-6-1247

[80] Halioua, L. and Anderson, J.J. (1990) Age and anthropometric determinants of radial bone mass in premenopausal Caucasian women: A cross-sectional study. Osteoporosis International, 11, 50-55. doi:10.1007/BF01880416

[81] Dawson-Hughes, B., Shipp, C., Sadowski, L. and Dallal, G. (1987) Bone density of the radius, spine, and hip in relation to percent of ideal body weight in postmenopausal women. Calcified Tissue International, 40, 310-314. doi:10.1007/BF02556691

[82] Ribot, C., Tremollieres, F., Pouilles, J.M., Louvet, J.P. and Guiraud, R. (1988) Influence of the menopause and aging on spinal density in French women. Bone Miner, 5, 89-97. doi:10.1016/0169-6009(88)90009-8

[83] Riedt, C.S., Cifuentes, M., Stahl, T., Chowdhury, H.A., Schlussel, Y. and Shapses, S.A. (2005) Overweight postmenopausal women lose bone with moderate weight reduction and $1 \mathrm{~g} /$ day calcium intake. Journal Bone Miner Research, 20, 455-463. doi:10.1359/JBMR.041132

[84] Villareal, D.T., Fontana, L., Weiss, E.P., Racette, S.B., Steger-May, K. and Schechtman, K.B. (2006) Bone mineral density response to caloric restriction-induced weight loss or exercise-induced weight loss: A randomized controlled trial. Archive International Mededicine, 166, 25022510. doi:10.1001/archinte.166.22.2502

[85] Hogan, S.L. (2005) The effects of weight loss on calcium and bone. Critical Care Nurses, 28, 269-275.

[86] Terkeltaub, R.A. (2003) Clinical practice. Gout-The New England Journal of Medicine, 349, 1647-1655. doi:10.1056/NEJMcp030733

[87] Schlesinger, N. and Schumacher Jr., H.R. (2001) Gout: Can management be improved? Current Opinion Rheumatology, 13, 240-244. doi:10.1097/00002281-200105000-00016

[88] Kramer, H.M. and Curhan, G. (2002) The association between gout and nephrolithiasis: The National Health and Nutrition Examination Survey III, 1988-1994. Amer- ican Jounal of Kidney Disease, 40, 37-42.

[89] Arromdee, E., Michet, C.J., Crowson, C.S., O’Fallon, W.M. and Gabriel S.E. (2002) Epidemiology of gout: Is the incidence rising? Journal of Rheumatology, 29, 24032406.

[90] Saag, K.G. and Choi, H. (2006) Epidemiology, risk factors, and lifestyle modifications for gout. Arthritis Research \& Therapy, 8, S2. doi:10.1186/ar1907

[91] Roubenoff, R., Klag, M.J., Mead, L.A., Liang, K.Y., Seidler, A.J. and Hochberg, M.C. (1991) Incidence and risk factors for gout in white men. JAMA, 266, 30043007. doi:10.1001/jama.1991.03470210072035

[92] Takahashi, S., Yamamoto, T., Tsutsumi, Z., Moriwaki, Y., Yamakita, J. and Higashino, K. (1997) Close correlation between visceral fat accumulation and uric acid metabolism in healthy men. Metabolism, 46, 1162-1165. doi:10.1016/S0026-0495(97)90210-9

[93] Atkinson, M. and Maclaren, N. (1994) The pathogenesis of insulin-dependent diabetes mellitus. Natural England Journal of Medicine, 331, 1428-1436. doi:10.1056/NEJM199411243312107

[94] DeFronzo, R.A., Bonadonna, R.C. and Ferannini, E. (1992) Pathogenesis of NIDDM: A balanced overview. Diabetes Care, 15, 318-368. doi:10.2337/diacare.15.3.318

[95] Magnusson, I., Rothman, D.L., Katz, L.D., Shulman, R.G. and Shulman, G.I. (1992) Increased rate of gluconeogenesis in type II diabetes mellitus. A 13C nuclear magnetic resonance study. Journal of Clinical Investigation, 90, 1323-1327. doi:10.1172/JCI115997

[96] Shah, P., Vella, A., Basu, A., Basu, R., Schwenk, W.F. and Rizza, R.A. (2000) Lack of suppression of glucagon contributes to postprandial hyperglycemia in subjects with type 2 diabetes mellitus. Journal of Clinical Endocrinology Metabolism, 85, 4053-4059. doi:10.1210/jc.85.11.4053

[97] Ali, Y.S., Linton, M.F. and Fazio, S. (2008) Targeting cardiovascular risk in patients with diabetes: Management of dyslipidemia. Current Opinion in Endocrinology, Diabetes and Obesity, 2, 142-146. doi:10.1097/MED.0b013e3282f5ff98

[98] Xie, W., Xing, D. and Zhao, Y. (2005) A new tactic to treat postprandial hyperlipidemia in diabetic rats with gastroparesis by improving gastrointestinal transit. Europion Journal of Pharmacology, 510, 113-120.

[99] Xie, W. and Du, L. (2005) High-cholesterol diets impair short-term retention of memory in alloxan-induced diabetic mice, but not acquisition of memory nor retention of memory in prediabetic mice. Life Science, 77, 481-495. doi:10.1016/j.lfs.2004.08.044

[100] Xie, W.D., Nie, Y., Du, L.J, Zhang, Y.O. and Cai, G.P. (2007) Preventive effects of fenofibrate and vitamin C on the development of type 2 diabetes and its complications in NIH mice induced by small-dose streptozotocin and lard. Pharmacology Research, 55, 392-399. doi:10.1016/j.phrs.2007.01.014

[101] Zimmet, P., Alberti, K.G.M.M. and Shaw, J. (2001) Global and societal implications of the diabetes epidem- 
ics. Nature, 414, 782-787. doi:10.1038/414782a

[102] Pandey, R., Kumar, N., Yadav, M., Nagpal, R., Jain, S. and Yadav, H. (2013) Anti-diabetic compounds and their patent information: An update. Recent Patents on Inflammation \& Allergy Drug Discovery, in Press. doi:10.2174/187221313804004745

[103] Knowler, W.C., Barrett-Connor, E. and Fowler, S.E. (2002) Diabetes Prevention Program Research Group. Reduction in the incidence of type 2 diabetes with lifestyle intervention or metformin. England Journal of Medicine, 346, 393-403.

[104] Scarvell, J. and Elkins, M.R. (2011) Aerobic exercise is beneficial for people with rheumatoid arthritis. Brazilians Journal of Sports Medicine, 45, 1008-1009. doi:10.1136/bjsports-2011-090388

[105] Batterham, S.I, Heywood, S. and Keating, J.L. (2011) Systematic review and meta-analysis comparing land and aquatic exercise for people with hip or knee arthritis on function, mobility and other health outcomes. BMC Musculoskeleton Disorder, 12, 123. doi:10.1186/1471-2474-12-123

[106] Soni, A. (2011) Top 10 most costly conditions among men and women, 2008: Estimates for the US civilian non-institutionalized adult population, age 18 and older. http://www.meps.ahrq.gov/mepsweb/data_files/publicatio ns/st331/stat331.pdf.

[107] Cowie, C.C., Rust, K.F. and Ford, E.S. (2009) Full accounting of diabetes and pre-diabetes in the US population in 1988-1994 and 2005-2006. Diabetes Care, 32, 287294. doi:10.2337/dc08-1296

[108] Centers for Disease Control and Prevention (CDC) (2008) Arthritis as a potential barrier to physical activity among adults with diabetes-United States, 2005 and 2007. Morbidity and Mortality Weekly Report, 57, 486-489

[109] Centers for Disease Control and Prevention (CDC) (2007) National and state medical expenditures and lost earnings attributable to arthritis and other rheumatic conditionsUnited States, 2003. Morbidity and Mortality Weekly Report, 56, 4-7.

[110] Centers for Disease Control and Prevention (CDC) (2011) Prevalence of doctor-diagnosed arthritis and arthritis-attributable effects among Hispanic adults, by Hispanic subgroup-United States, 2002, 2003, 2006, and 2009. Morbidity and Mortality Weekly Report, 60, 167-171.

[111] Nolan, C.J., Damm, P. and Prentki, M. (2008) Type 2 diabetes across generations: From pathophysiology to prevention and management. Lancet, 378, 169-181. doi:10.1016/S0140-6736(11)60614-4

[112] Murphy, L., Schwartz, T.A. and Helmick, C.G. (2008) Lifetime risk of symptomatic knee osteoarthritis. Arthritis Rheumatology, 59, 1207-1213. doi:10.1002/art.24021

[113] Furner, S.E., Hootman, J.M., Helmick, C.G., Bolen, J. and Zack, M.M. (2011) Health-related quality of life of US adults with arthritis: Analysis of data from the behavioral risk factor surveillance system, 2003, 2005, and 2007. Arthritis Care Research, Hoboken.

[114] Chenge, Y.J., Imperatore, G., Caspersen, C.J., Gregg, E.W., Albright, A.L. and Helmick, C.G. (2011) Prevalence of diagnosed arthritis and arthritis-attributable activity limitation among adults with and without diagnosed diabetes: United States, 2008-2010. Diabetes Care, 8, 16861691.

[115] Susan, F.K. and Simon, L. (1994) Joint and bone manifestations of diabetes mellitus in Joslin's Diabetes Mellitus. In: Ronal, K.C. and Weir, G.C., Eds., 13th Edition, Lea \& Febiger, Philadelphia, 912-917.

[116] Jung, Y., Hohmann, T.C. and Gerneth, J.A. (1998) Diabetic hand syndrome. Metabolism, 20, 1008-1015. doi:10.1016/0026-0495(71)90023-0

[117] Grgic, A., Rosenbloom, A.L. and Weber, F.T. (1976) Joint contractures common manifestation of childhood diabetes mellitus. Journal of Pediatrices, 88, 584-588. doi:10.1016/S0022-3476(76)80011-X

[118] Kapoor, A. and Sibbitt Jr., W.L. (1980) Contractures in diabetes mellitus: The syndrome of limited joint mobility, Arthritis Rheumatology, 18, 168-180.

[119] Rosenbloom, A.L., Silverstein, J.H. and Lezotte D.C. (1981) Limited joint mobility in childhood diabetes mellitus indicates increased risk for microvascular disease. England Journal of Medicine, 305, 191-194. doi:10.1056/NEJM198107233050403

[120] Steinbrocker, O. (1947) The shoulder-hand syndrome: Associated painful homolateral disability of the shoulder and hand with swelling and atrophy of the hand. American Journal of Medicine, 3, 402-407. doi:10.1016/0002-9343(47)90170-8

[121] Steinbrocker, O. and Argyros, T.G. (1958) The shoulderhand syndrome: Present status as a diagnostic and therapeutic entity. Medicine Clinical North America, 42, 15331553.

[122] Crisp, A.J. and Heathcoate, J.G. (1984) Connective tissue abnormalities in diabetes mellitus. Journal of the Royal College of Physicians, 18, 132-141.

[123] Gray, R.G. and Gottlieb, N.L. (1976) Rheumatic disorders associated with diabetes mellitus: Literature review. Arthritis Rheumatology, 6, 19-34.

[124] Holt, P.J.L. (1981) Rheumatological manifestations of diabetes mellitus. Clinical Rheumatology Disease, 7, 723746.

[125] Solomon, D.H., Love, T.J., Canning, C. and Schneeweiss S. (2010) Risk of diabetes among patients with rheumatoid arthritis, psoriatic arthritis and psoriasis. Annual Rheumatology Disease, 69, 2114-2117. doi:10.1136/ard.2009.125476

[126] Han, C., Robinson, D.W. and Hackett, M.V. (2006) Cardiovascular disease and risk factors in patients with rheumatoid arthritis, psoriatic arthritis, and ankylosing spondylitis. Journal of Rheumatology, 33, 2167-2172.

[127] Rincon, I.D., Williams, K., Stern, M.P., Freeman, G.L. and Escalante, A. (2001) High incidence of cardiovascular events in a rheumatoid arthritis cohort not explained by traditional cardiac risk factors. Arthritis Rheumatology, 44, 2737-2745. doi:10.1002/1529-0131(200112)44:12<2737::AID-ART4 60>3.0.CO;2-\#

[128] Chung, C.P., Oeser, A. and Solus, J.F. (2008) Prevalence 
of the metabolic syndrome is increased in rheumatoid arthritis and is associated with coronary atherosclerosis. Atherosclerosis, 196, 756-763. doi:10.1016/j.atherosclerosis.2007.01.004

[129] Dessein, P.H., Joffe, B.I. and Stanwix, A.E. (2002) Effects of disease modifying agents and dietary intervention on insulin resistance and dyslipidemia in inflammatory arthritis: A pilot study. Arthritis Research, 4, 12-21. doi:10.1186/ar597

[130] Simard, J.F. and Mittleman, M.A. (2007) Prevalent rheumatoid arthritis and diabetes among NHANES III participants aged 60 and older. Journal of Rheumatology, 34, 469-473.

[131] Liao, K.P., Gunnarsson, M. and Kallberg, H. (2009) Specific association of type 1 diabetes mellitus with anti-cyclic citrullinated peptide-positive rheumatoid arthritis. Arthritis Rheumatology, 60, 653-660. doi:10.1002/art.24362

[132] Harris, M.I, Flegal, K.M., Cowie, C.C., Eberhardt, M.S., Goldstein, D.E., Little, R.R., Wiedmeyer, H.M., ByrdHolt, D.D. (1998) Prevalence of diabetes, impaired fasting glucose, and impaired glucose tolerance in US adults: The Third National Health and Examination Survey, 1988-1994. Diabetes Care, 21, 518-524. doi:10.2337/diacare.21.4.518

[133] Boyle, J.P., Honeycutt, A.A., Narayan, K.M., Hoerger, T.J., Geiss, L.S., Chen, H. and Thompson, T.J. (2001) Projection of diabetes burden through 2050: Impact of changing demography and disease prevalence in the US. Diabetes Care, 24, 1936-1940. doi:10.2337/diacare.24.11.1936

[134] Nathan, D.M. (1993) Long-term complications of diabetes mellitus. New England Journal of Medicine, 328, 1676-1685. doi:10.1056/NEJM199306103282306

[135] Songer, T. (1995) Disability in diabetes. In: Harris, M.I., Cowie, C.C., Stern, M.P., Boyko, E.J., Reiber, G.E., Bennett, P.H., Eds., Diabetes in America, 2nd Edition, Washington, 429-448.

[136] Centers for Disease Control and Prevention (1997) Diabetes surveillance Atlanta, GA. US Department of Health and Human Services.

[137] Gregg, E.W., Beckles, G.L., Williamson, D.F., Leveille, S.G., Langlois, J.A., Engelgau, M.M. and Narayan, K.M. (2000) Diabetes and physical disability among US adults. Diabetes Care, 23, 1272-1277. doi:10.2337/diacare.23.9.1272

[138] Guralnik, J.M., LaCroix, A.Z., Abbott, R.D., Berkman, L.F., Satterfield, S., Evans, D.A. and Wallace, R.B. (1993) Maintaining mobility in late life. I. Demographic characteristics and chronic conditions. American Journal of Epidemiology, 137, 845-857.

[139] Pinsky, J.L., Jette, A.M., Branch, L.G., Kannel, W.B. and Feinleib, M. (1990) The Framingham Disability Study: Relationship of various coronary heart disease manifestations to disability in older persons living in the community. American Journal of Public Health, 80, 1363-1368. doi:10.2105/AJPH.80.11.1363

[140] Clark, D.O., Stump, T.E. and Wolinsky, F.D. (1998) Predictors of onset of and recovery from mobility difficulty among adults aged 51 - 61 years. American Journal of Epidemiology, 148, 63-71.

doi:10.1093/oxfordjournals.aje.a009561

[141] Lee, P.P., Spritzer, K. and Hays, R.D. (1997) The impact of blurred vision on functioning and wellbeing. Ophthalmology, 104, 390-396.

[142] Resnick, H.E., Vinik, A.I., Schwartz, A.V., Leveille, S.G., Brancati, F.L., Balfour, J. and Guralnik, J.M. (2000) Independent effects of peripheral nerve dysfunction on lower extremity physical function in old age: The Women's Health and Aging Study. Diabetes Care, 13, 1642-1647. doi:10.2337/diacare.23.11.1642

[143] Fried, L.P., Tangen, C.M., Walston, J, Newman, A.B., Hirsch, C., Gottdiener, J., Seeman, T., Tracy, R., Kop, W.J., Burke, G. and McBurnie, M.A. (2001) Frailty in older adults: evidence for a phenotype. Journal of Gerontology Medicine and Science, 56A, 146-156.

[144] Svenson, K.L., Pollare, T., Lithell, H. and Hallgren, R. (1988) Impaired glucose handling in active rheumatoid arthritis: Relationship to peripheral insulin resistance. Metabolism, 37, 125-130. doi:10.1016/S0026-0495(98)90005-1

[145] Dessein, P.H., Stanwix, A.E. and Joffe, B.I. (2002) Cardiovascular risk in rheumatoid arthritis versus osteoarthritis: Acute phase response related decreased insulin sensitivity and high-density lipoprotein cholesterol as well as clustering of metabolic syndrome features in rheumatoid arthritis. Arthritis Research, 4, 5-8. doi:10.1186/ar428

[146] Dessein, P.H., Joffe, B.I., Stanwix, A.E., Christian, B.F. and Veller, M. (2002) The acute phase response does not fully predict the presence of insulin resistance and dyslipidemia in inflammatory arthritis. Journal of Rheumatology, 29, 462-466.

[147] Dessein, P.H., Joffe, B.I., Stanwix, A., Botha, A.S. and Moomal, Z. (2004) Glucocorticoids and insulin sensitivity in rheumatoid arthritis. Journal of Rheumatology, 31, 867-874.

[148] Han, C., Robinson Jr., D.W., Hackett, M.V., Paramore, L.C., Fraeman, K.H. and Bala, M.V. (2006) Cardiovascular disease and risk factors in patients with rheumatoid arthritis, psoriatic arthritis, and ankylosing spondylitis. Journal of Rheumatology, 33, 2167-2172.

[149] Solomon, D.H., Karlson, E.W. and Rimm, E.B. (2003) Cardiovascular morbidity and mortality in women diagnosed with rheumatoid arthritis. Circulation, 107, 13031307. doi:10.1161/01.CIR.0000054612.26458.B2

[150] Rincon, I., Williams, K., Stern, M.P., Freeman, G.L. and Escalante, A. (2001) High incidence of cardiovascular events in a rheumatoid arthritis cohort not explained by traditional risk factors. Arthritis Rheumatology, 44, 27372745.

doi:10.1002/1529-0131(200112)44:12<2737::AID-ART4 60>3.0.CO;2-\#

[151] Simard, J.F. and Mittleman, M.A. (2007) Prevalent rheumatoid arthritis and diabetes among NHANES III participants aged 60 and older. Journal of Rheumatology, 34, 469-473.

[152] Kaipiainen-Seppanen, O., Aho, K., Isomaki, H. and La- 
akso, M. (1996) Incidence of rheumatoid arthritis in Finland during 1980-1990. Annual Rheumatology Disease, 55, 608-611. doi:10.1136/ard.55.9.608

[153] Doran, M.F., Pond, G.R., Crowson, C.S., O’Fallon, W.M. and Gabriel S.E. (2002) Trends in incidence and mortality in rheumatoid arthritis in Rochester, Minnesota over a 40-year period. Arthritis Rheumatology, 46, 625-631. doi:10.1002/art.509

[154] Hakala, M., Vahlberg, T. and Niemi, P.M. (1992) No association between rheumatoid arthritis and insulin dependent diabetes mellitus: An epidemiologic and immunogenetic study. Journal of Rheumatology, 19, 856-858. 